\title{
Agricultural injuries encountered in Giresun, which is an agricultural city of Turkey
}

\author{
Selim Turfan $^{1} \odot$, Faruk Özşahin ${ }^{1} \odot$, Gökhan Uzun ${ }^{1} \odot$, Bora Arslan$^{1} \odot$, Mustafa Tolga Gürgen²$\odot$, Tuğrul \\ Kesicioğlu ${ }^{3} \odot$
}

${ }^{1}$ Department of Emergency Medicine, Giresun University, Prof. Dr. Illhan Özdemir Training and Research Hospital, Giresun, Turkey ${ }^{2}$ Department of Thoracic Surgery, Giresun University, Prof. Dr. Ilhan Özdemir Training and Research Hospital, Giresun, Turkey ${ }^{3}$ Department of General Surgery, Giresun University, Prof. Dr. Illhan Özdemir Training and Research Hospital, Giresun, Turkey

\begin{abstract}
Objectives: This study aimed to determine the demographic and clinical features of gardening injuries in an agricultural city and to provide some suggestions to reduce the incidence of agricultural injuries.

Methods: This study assessed 419 gardening injuries that were admitted to the emergency department of Giresun University Prof. Dr. Ilhan Özdemir Training and Research Hospital between June 30, 2015 and November 1, 2015. We retrospectively examined all the documents, x-rays, tomographies, and tomography reports related to the cases.
\end{abstract}

Results: Falls from a height (19.3\%), falls (31.5\%), foreign body crashes (FBCs) (14.8\%), sharp-penetrating object injuries (SPOIs) (29.8\%), and motorized/motorless device injuries (MMDIs) (4.5\%) were the major categories of gardening injuries. Most of the falls from a height were from a tree (86\%), primarily fig trees $(54.3 \%)$. SPOIs primarily affected the hand-wrist area with 82 cases $(65.6 \%)$; the most common sharp tools that caused injury were sickle-scythes $(47.2 \%)$ and axes $(35.2 \%)$. FBCs frequently affected the eyes $(48.4 \%)$ and head region (17.7\%), and tree branches were the most common foreign bodies causing such crashes (38.7\%). MMDIs were caused primarily by haymaker harvester machines $(42 \%)$. Three cases died $(0.7 \%)$, and 305 cases $(72.8 \%)$ were discharged after emergency treatment. Additionally, 115 cases $(27.5 \%)$ were hospitalized, 11 cases underwent urgent surgery, and 63 cases underwent elective surgery. Using uncuttable gloves, socks, and knee-guards could prevent $88 \%$ of SPOIs. Furthermore, eyewear and head guards could prevent $60.1 \%$ of $\mathrm{FBC}$ injuries. The usage of fall arrest equipment particularly for only fig and pear tree types could prevent $68.6 \%$ of the falls from a tree.

Conclusions: Gardening injuries are significant traumas in agricultural regions. By implementing simple and cheap security measures, we can prevent destrucitive traumas.

Keywords: injury, agricultural injury, gardening injury, farm injury, back yard injury, trauma, work-related injury



iresun is a city on the northeastern part of Turkey that is famous for its nature and greens and blues. Giresun is located on the shore of the Black Sea. Turkey is a pioneer in hazelnut production world- wide, and Giresun ranks first in this production with its high-quality hazelnuts.

Turkey is the leader of world nut export with $65.5 \%$. Giresun is on the first rank of nut export 
among the cities of Turkey.Almost all the locals in Giresun have their own nut, fruit, and vegetable gardens. In addition to nuts, they commonly grow fruits, including cherries, apples, pears, figs, grapes, plums, and cherry laurel, and vegetables, including black cabbage, corn, potatoes, green beans, parsley, fresh mint, and lettuce.

gardens are mostly grown on inclined terrain, which can easily cause injuries such as falls. Stones, wood, soil, and weeds can slip down and hit a human. Furthermore, the gardeners use sharp objects during gardening, which can cause injuries.

Hazelnut trees are short, and the nuts are picked by pulling the branches down or by picking the nuts up from the ground. During this activity, the branches can hit the head, particularly the eyes, and dust can transfer foreign bodies to the eyes. Moreover, some people use motorized or motorless devices to carry the crops, separate the nut and its green shell, etc., and these devices can cause injuries.

Our hospital has experienced many cases of gardening injuries. Therefore, we aimed to identify the most common types of gardening injuries and suggest some solutions to reduce the damage.

\section{METHODS}

This study assessed gardening injury cases that were admitted to the emergency department of the Giresun University Prof. Dr. Ilhan Özdemir Training and Research Hospital between June 30, 2015 and November 1, 2015. We retrospectively examined all the documents, $\mathrm{x}$-rays, tomographies, and tomography

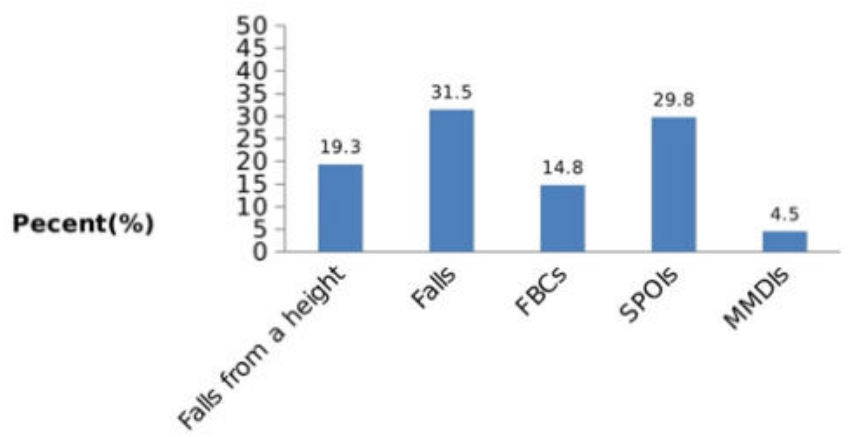

Fig. 1. Types of injuries. FBCs = Foreign body crashes, SPOIs = Sharp-penetrating object injuries, MMDIs = Motorized/Motorless device injuries. reports. Traffic accidents on the way to the garden, allergic reactions, insect bites, and animal-related injuries were not included in this study.

\section{Statistical Analysis}

The IBM SPSS 17.0 (IBM Corporation, Armonk, NY, USA) program was used to analyze the data.

\section{RESULTS}

The mean age of the study population was $49.4 \pm$ 18.0 years (range 3-97). Additionally, $66.6 \%(n=279)$ of cases were male and $33.4 \%(n=140)$ were female. The patients were most frequently admitted to the hospital in August (38.2\%), September (23.6\%), July $(22.4 \%)$, and October (14.8\%).

The most common types of injuries were falls $(31.5 \%, \mathrm{n}=132)$, sharp-penetrating object injuries (SPOIs) $(29.8 \%, \mathrm{n}=125)$, falls from a height $(19.3 \%$, $\mathrm{n}=81$ cases), foreign body crashes (FBCs) $(14.8 \%, \mathrm{n}$ $=62)$, and motorized $/$ motorless device injuries (MMDIs) $(4.5 \%, \mathrm{n}=19)$, as shown in Fig. 1 .

The SPOIs were caused primarily by sicklescythes $(47.2 \%, \mathrm{n}=59)$, axes $(35.2 \%, \mathrm{n}=44)$, saw machines $(12 \%, \mathrm{n}=15)$, string trimmers $(4.8 \%, \mathrm{n}=$ $6)$, and curved knifes $(0.8 \%, n=1)$. The body parts most commonly affected by SPOIs were hands-wrists $(65.6 \%, \mathrm{n}=82)$, foot-ankle $(11.2 \%, \mathrm{n}=14)$, and knees $(11.2 \%, \mathrm{n}=14)$, as shown in Table 1 .

Table 1. Regions of sharp-penetrating object injuries (SPOIs)

\begin{tabular}{lcc}
\hline Region & Number of cases & Percent \\
\hline Hand-wrist & 82 & 65.6 \\
Knee & 14 & 11.2 \\
Foot-ankle & 14 & 11.2 \\
Arm & 4 & 3.2 \\
Shin & 3 & 2.4 \\
Forearm & 2 & 1.6 \\
Thigh & 2 & 1.6 \\
Head & 2 & 1.6 \\
Elbow & 1 & 0.8 \\
Ear & 1 & 0.8 \\
Total & 125 & 100 \\
\hline
\end{tabular}


There were three primary types of falls from a height: from a tree $(87 \%, \mathrm{n}=70)$, from a steep slope $(12 \%, \mathrm{n}=10)$, and from long ladders $(1 \%, \mathrm{n}=1)$. As shown in Table 2, the falls were mostly from fig trees $(54.3 \%, \mathrm{n}=38)$, pear trees $(14.3 \%, \mathrm{n}=10)$, walnut trees $(5.7 \%, \mathrm{n}=4)$, and cherry laurel trees $(5.7 \%, \mathrm{n}=$ 4).

FBCs were caused by tree branches $(38.7 \%, \mathrm{n}=$ $24)$, stones $(19.4 \%, \mathrm{n}=12)$, soil-weeds-dust $(19.4 \%$, $\mathrm{n}=12)$, and wood-trunks $(17.7 \%, \mathrm{n}=11)$, as shown in Table 3.

As shown in Table 4, the body parts most commonly affected by FBCs were the eyes $(48.4 \%, \mathrm{n}$ $=30)$, head $(17.7 \%, \mathrm{n}=11)$, and foot-ankle $(11.3 \%, \mathrm{n}$ $=7$ ).

Most instances of MMDIs occurred from using chugs $(42 \%, \mathrm{n}=8)$, followed by haymaker harvester machines $(21 \%, n=4)$, telphers $(21 \%, n=4)$, hazelnut ventilators $(11 \%, \mathrm{n}=2)$, and quad bikes $(5 \%, \mathrm{n}=1)$, as shown in Fig. 2.

The primary clinical findings were only soft tissue damage $(37.7 \%, \mathrm{n}=158)$, simple cuts $(28.9 \%, \mathrm{n}=$ $121)$, extremity fractures $(14.1 \%, \mathrm{n}=59)$, tendon cuts $(9.3 \%, \mathrm{n}=39)$, and vertebra fractures $(8.6 \%, \mathrm{n}=36)$.

Table 5 shows the other clinical findings.

The vertebral fractures were primarily located in the lumbar $(47.2 \%, \mathrm{n}=17)$, thoracic $(36.1 \%, \mathrm{n}=13)$, and cervical $(5.6 \%, \mathrm{n}=2)$ spine. Two cases $(5.6 \%)$ had both cervical-thoracic fractures, and two cases $(5.6 \%)$ had both thoracic-lumbar fractures.

In total, $305(72.8 \%)$ patients were discharged after receiving treatment in the emergency department. Additionally, 105 (25.1\%) patients were hospitalized and $10(2.4 \%)$ patients were transferred to another hospital. Three patients $(0.7 \%)$ died in our hospital.

The neurosurgery department treated $28.6 \%$ (30 cases) of the hospitalized patients whereas the plastic reconstructive surgery, orthopedics, and thoracic surgery departments treated $22.9 \%(\mathrm{n}=24), 21.9 \%(\mathrm{n}$ $=23)$, and $13.3 \%(n=14)$ of the patients, respectively. Additionally, $10.5 \%(\mathrm{n}=11)$ of patients were admitted to the general surgery department and $1.9 \%(\mathrm{n}=2)$ were admitted to pediatric surgery. Only one patient $(0.9 \%)$ who had been admitted to the ophthalmology department was hospitalized.

An urgent operation was performed in eleven cases, six $(55.5 \%)$ of which were performed by plastic-reconstructive surgeons and five $(45.5 \%)$ of
Table 2. Type of the tree

\begin{tabular}{lcc}
\hline Type of the tree & Number of cases & Percent \\
\hline Fig & 38 & 54.3 \\
\hline Pear & 10 & 14.3 \\
\hline Walnut & 4 & 5.7 \\
\hline Cherry laurel & 4 & 5.7 \\
\hline Plun & 3 & 4.3 \\
\hline Hazelnut & 3 & 4.3 \\
\hline Apple & 2 & 2.9 \\
\hline Linden & 2 & 2.9 \\
\hline Cherry & 2 & 2.9 \\
\hline Grape & 2 & 2.9 \\
Total & $\mathbf{7 0}$ & $\mathbf{1 0 0}$ \\
\hline
\end{tabular}

Table 3. Reasons of foreign body crashes (FBCs)

\begin{tabular}{lcc}
\hline $\begin{array}{l}\text { Foreign body crash } \\
\text { (FBC) }\end{array}$ & $\begin{array}{c}\text { Number of } \\
\text { cases }\end{array}$ & Percent \\
\hline Tree branch & 24 & 38.7 \\
\hline Stone & 12 & 19.4 \\
Soil-weed-dust & 12 & 19.4 \\
Wood-trunk & 11 & 17.7 \\
\hline Nail & 2 & 3.2 \\
Water resorvoir cover & 1 & 1.6 \\
\hline Total & $\mathbf{6 2}$ & $\mathbf{1 0 0}$ \\
\hline
\end{tabular}

Table 4. Regions of foreign body crashes (FBCs)

\begin{tabular}{lcc}
\hline Region & Number of cases & Percent \\
\hline Eye & 30 & 48.4 \\
Head & 11 & 17.7 \\
\hline Foot-ankle & 7 & 11.3 \\
Shin & 3 & 4.8 \\
\hline Ear & 3 & 4.8 \\
\hline Hand-wrist & 2 & 3.2 \\
Thigh & 2 & 3.2 \\
Chest-back & 2 & 3.2 \\
Forearm & 1 & 1.6 \\
Thigh + Chest-back & 1 & 1.6 \\
Total & $\mathbf{6 2}$ & $\mathbf{1 0 0}$ \\
\hline
\end{tabular}






Fig. 2. Types of motorized/motorless device injuries.

\section{Table 5. Clinical Findings}

\begin{tabular}{lcc}
\hline Clinical finding & $\begin{array}{c}\text { Number of } \\
\text { cases }\end{array}$ & Percent \\
\hline Only soft tissue damage & 158 & 37.7 \\
\hline Simple cut & 121 & 28.9 \\
\hline Extremity fractures & 59 & 14.1 \\
Tendon cut & 39 & 9.3 \\
\hline Vertebra fractures & 36 & 8.6 \\
Intrathoracal injury & 23 & 5.5 \\
\hline Amputation/circulatory & 10 & 2.4 \\
impairment & & \\
Intraabdominal injury & 7 & 1.7 \\
Intracranial injury & 5 & 1.2 \\
Wide tissue defect or & 5 & 1.2 \\
need of flap & & \\
Shoulder dislocation & 3 & 0.7 \\
Total & $\mathbf{4 1 9}$ & $\mathbf{1 0 0}$ \\
\hline
\end{tabular}

which were performed by neurosurgeons. Sixty-three patients underwent elective operations in the following departments: plastic reconstructive surgery $(47.6 \%, \mathrm{n}$ $=30)$, orthopedics $(34.9 \%, \mathrm{n}=22)$, neurosurgery $(14.3 \%, \mathrm{n}=9)$, general surgery $(1.6 \%, \mathrm{n}=1)$, and ophthalmology $(1.6 \%, \mathrm{n}=1)$.

\section{DISCUSSION}

Agricultural injuries are increasing daily [1] and have a high risk of mortality and morbidity. Agricultural populations, governments, and municipal authorities should pay attention to gardening injuries and tighten safety measures.

The mean age of the injured population in this study was younger [2] or similar [3, 4] to that reported in previous studies. In Giresun, people tend to work in their own gardens with few seasonal workers. Our study included both a three-year-old child who was picking up hazelnuts from the ground and a 97-yearold woman who was helping her children in a hazelnut garden.

Das [2] reported 323 cases of farming injuries in West Bengal in India. Most of the patients were injured by hand tools (64.7\%), followed by injuries from farm machinery $(29.1 \%)$ and others $(6.2 \%)$ including dermatologic and respiratory problems, etc. [2]. Browning et al. [5] reported on the incidence of injuries from falls $(24.9 \%)$, machinery $(22.5 \%)$, woodcutting (14.6\%), and animal-related events (14.3\%) in Kentucky among the farmers who were older than 55. Zhou and Roseman [6] reported that the external causes of farm operator injuries in Alabama were machinery (28.6\%), falls (23.2), and animal-related $(12.5 \%)$. Twari et al. [7] reported on the agricultural injuries of Central India. They highlighted the incidence of injuries from farm machinery $(77.6 \%)$, hand tools $(11.8 \%)$, and others $(10.6 \%)$, including snakebites, wells, etc. Another study revealed that $30.1 \%$ of injuries were fall-related, $39.8 \%$ were machine-related, and $16.1 \%$ were animal-related [4]. In our study, many of the patients were injured in their own gardens; few seasonal workers were included. We did not include dermatologic, respiratory, or animalrelated injuries in our study. Some motorized or motorless vehicles caused injuries in our study; however, Giresun has rugged terrains, so falls were the primary cause of injury. Sharp objects or hand tools are also used frequently in Giresun. FBCs are relatively commonly because of the rugged terrain and hazelnut tree branches.

One previous study reported on 222 sharp and penetrating object injuries that were primary caused by daos $(\mathrm{n}=144,60 \%)$, spades $(\mathrm{n}=19,8 \%)$, sickles $(\mathrm{n}=18,7 \%)$, and axes $(\mathrm{n}=8,3 \%)$; feet and legs were the most frequently injured body parts [8]. Another study reported on injuries with hand tools that were caused primarily by spades, sickles, cutters, etc. [2]. Zhou and Roseman [6] reported that the limbs were the most frequently injured body part. Twari et al. [7] 
reported that $11.8 \%$ of injuries were caused by hand tools, primarily sickles and pickaxes. We found that $71.2 \%$ of injuries were upper extremity injuries and $26.5 \%$ were lower extremity injuries. The dao and spade were not used as tools in our region. Additionally, $65.6 \%$ of injuries were hand-wrist injuries and $11.2 \%$ were foot-ankle injuries. If the authorities support the use of only uncuttable clothe for distal parts of the extremities, we could eliminate $76.8 \%$ of SPOIs. Additionally, the usage of uncuttable knee-guards will help prevent $88 \%$ of SPOIs.

Falls from a height are very dangerous and can result in death. Falls from trees are the major cause of this type of injury. Some tree types are more hazardous than others; these tree types can be determined locally, and measures can be taken to prevent falls from these trees. Previous studies showed that coconut [9], walnut [10], and other trees were the most hazardous types in those study regions. In our region, patients most frequently fell from fig $(54.3 \%)$ and pear trees $(14.3 \%)$. If the authorities support the use of fall arrest equipment particularly for these tree types, $68.6 \%$ of the falls will be preventable for Giresun citizens.

FBCs are an important type of agricultural injury. In previous studies, falling branches, falling fruits, machine-related injuries, etc. are mentioned as factors for injury [11-14]. In our region, patients were often struck by hazelnut tree branches in the eyes and experienced soil-weed-dust related injuries of the eyes. Some of these cases resulted in ocular rupture. The population's awareness of eye health is very poor. Authorities should advise the use of eye protectors, eye glasses, or goggles, particularly for harvesting hazelnuts. In turn, $48.4 \%$ of these injuries can be prevented. Many studies advise the use of eyewear such as goggles to prevent work-related injuries to the eye [14-16]. Additionally, the use of head guards can prevent $60.1 \%$ of $\mathrm{FBC}$ injuries.

Simple cuts and soft tissue damage were the most common injuries, similar to previous studies $[2,7]$. Farm machinery and motorized/motorless devices such as tractors, threshers, animal-drawn puddlers, winnowers, electric pump sets, power tillers, and speed sprayers were not frequently used in Giresun; however, other studies reported on injuries caused by these devices [2, 7, 17, 18]. Chugs, telphers, and haymaker harvester machines are more commonly used in Giresun.
Allen et al. [3] published an original article on 2294 farm-related injuries in North Carolina. In total, 82.1\% of the patients were discharged from the emergency department, $12.1 \%$ were admitted to the hospital, $3.8 \%$ were transferred to another hospital, and $0.4 \%$ died [3]. In one study, the hospitalization rate was $43.9 \%$ and the mortality rate was $1.6 \%$ [4]. Our study included three patients who died from a gardening injury. We do not know the outcomes of the patients who were transferred to other hospitals; thus, the mortality may be higher. One of our patients died from a simple fall. She experienced a traumatic subarachnoidal hemorrhage. Another patient died as a result of a quad bike crash. The last patient had three toes amputated on his foot after a piece of wood crushed it; he died as a result of complications of the operation.

\section{Limitations}

This study was a retrospective study and a considerable amount of cases may be overlooked. Study duration was restricted to 5 months. The cases that transferred to the other hospitals could not be followed so we don't know the real mortality and morbidity. Insect bites, traffic accidents of workers, animal-related injuries, allergic diseases were not included in this study.

\section{CONCLUSION}

Gardening injuries are important traumas for agricultural regions.If we tighten security measures simply and cheaply we can prevent destructive traumas.

\section{Conflict of interest}

The authors disclosed no conflict of interest during the preparation or publication of this manuscript.

\section{Financing}

The authors disclosed that they did not receive any grant during conduction or writing of this study.

\section{REFERENCES}

1. Missikpode C, Peek-Asa C, Young T, Swanton A, Leinenkugel 
$\mathrm{K}$, Torner J. Trends in non-fatal agricultural injuries requiring trauma care. Inj Epidemiol 2015;2:30.

2. Das B. Agricultural work related injuries among the farmers of West Bengal, India. Int J Inj Contr Saf Promot 2014;21:20515 .

3. Allen DL, Kearney GD, Higgins S. A descriptive study of farm-related injuries presenting to emergency departments in North Carolina: 2008-2012. J Agromedicine 2015;20:398-408.

4. Pfortmueller CA, Kradolfer D, Kunz M, Lehmann B, Lindner $\mathrm{G}$, Exadaktylos AK. Injuries in agriculture - injury severity and mortality. Swiss Med Wkly 2013;143:w13846.

5. Browning SR, Truszczynska H, Reed D, McKnight RH. Agricultural injuries among older Kentucky farmers: The Farm Family Health and Hazard Surveillance Study. Am J Ind Med 1998;33:341-53.

6. Zhou C, Roseman JM. Agricultural injuries among a population-based sample of farm operators in Alabama. Am J Ind Med 1994;25:385-402.

7. Tiwari PS, Gite LP, Dubey AK, Kot LS. Agricultural injuries in Central India: nature, magnitude, and economic impact. J Agric Saf Health 2002;8:95-111.

8. Patel T, Pranav PK, Biswas M. Nonfatal agricultural workrelated injuries: a case study from Northeast India. Work 2018;59:367-74.

9. Negin J, Vizintin P, Housaia P, Martiniuk ALC. Barking up the wrong tree:injuries due to falls from tree in Solomon Islands.
Med J Aust 2014;201:698-700.

10. Karbeyaz K, Şenlik M, Yetiş Y, Güneş A, Yılmaz A. [Evaluation of deaths caused by falling from trees in the elderly]. Osmangazi J Med 2018;40:34-9. [Article in Turkish]

11. Rehan R, Jones P, Abdeen H, et al. The dangers to children from coconut tree trauma, in KiraKira, Solomon Islands: a retrospective clinical audit. Arch Public Health 2016;74:14.

12. Barss P, Dakulala P, Doolan M. Falls from trees and tree associated injuries in rural Melanesians. Br Med J (Clin Res Ed) 1984;289:1717-20.

13. Centers for Disease Control and Prevention (CDC). Eye injuries to agricultural workers--Minnesota, 1992-1993. MMWR Morb Mortal Wkly Rep 1995;44:364-6.

14. Chatterjee S, Agrawal D. Primary prevention of ocular injury in agricultural workers with safety eyewear. Indian J Ophthalmol 2017;65:859-64.

15. Welch LS, Hunting KL, Mawudeku A. Injury surveillance in construction: eye injuries. Appl Occup Environ Hyg 2001;16:755-62.

16. Yu TS, Liu H, Hui K. A case-control study of eye injuries in the workplace in Hong Kong. Ophthalmology 2004;111:70-4.

17. Lee K, Lim HS. Work-related injuries and diseases of farmers in Korea. Ind Health 2008;46:424-34.

18. Rautiainen RH, Reynolds SJ. Mortality and morbidity in agriculture in the United States. J Agric Saf Health 2002;8:25976. 